\title{
ODREĐIVANJE UTICAJA PO TEORIJI DRUGOG REDA METODOM KONAČNIH RAZLIKA
}

\author{
Besim Demirović ${ }^{1}$ \\ Zijad Požegić \\ Mirsad Topalović 3 \\ Nedim Osmić ${ }^{4}$
}

УДК: 517.962 .8

DOI:10.14415/konferencijaGFS 2016.034

Rezime: U ovom radu je prikazan postupak numeričkog modeliranja geometrijske nelinearnosti nosača primjenom metode konačnih razlika. Proračun presječnih sila $i$ pomjeranja je proveden iterativnim postupcima uzimajući u obzir uticaje drugog reda. Opisanim postupkom ravnoteža sistema se uspostavlja na deformisanom nosaču. Na taj način presječne sile imaju svoj doprinos na momente savijanja $i$ deformacije. Prikazanim metodama proračuna može se modelirati geometrijska nelinearnost nosača sa konstantnim ili promjenjivim poprečnim presjekom. Proračuni su urađeni numerički, a rezultati su kontrolisani u programskom paketu Tower. Prikazani su numerički rezultati pomjeranja $i$ sila, $i$ uspoređeni sa rezultatima dobijenim u programskom paketu. Kroz numeričke primjere je prezentiran postupak proračuna i izvršena analiza rezultata.

Ključne riječi: geometrijska nelinearnost, teorija drugog reda.

\section{UVOD}

Kod konstrukcija sa vitkim elementima dolazi do značajne deformacije elemenata nosača. Analizom deformisanog štapa spoljašnje opterećenje utiče na promjenu presječnih sila i deformacija. Pomjeranje ose štapa pri djelovanju opterećenja izaziva dodatne statičke uticaje koji se nazivaju uticaji drugog reda. Od svih uticaja drugog reda značajnu ulogu imaju momenti savijanja i deforamcije štapa, pa su u ovom radu analizirani. Momenti savijanja dobijeni po teoriji drugog reda kod nekih nosača se ne mogu zanemariti. Momenti savijanja u ovom radu su dobijeni iterativno sa postupnim približavanjem ravnotežnom stanju nosača.

\footnotetext{
${ }^{1}$ dr. sci. Besim Demirović, dipl. inž. građ., Univerzitet u Tuzli, Rudarsko-geološko-građevinski fakultet Tuzla, Univerzitetska broj 2, Tuzla, Bosna i Hercegovina, e-mail: besim_demirovic@yahoo.com

${ }^{2}$ dr. sci. Zijad Požegić, dipl. inž. građ., Univerzitet u Tuzli, Rudarsko-geološko-građevinski fakultet Tuzla, Univerzitetska broj 2, Tuzla, Bosna i Hercegovina, e - mail: zijad.pozegic@ untz.ba

${ }^{3}$ dr. sci. Mirsad Topalović, dipl. inž. građ., Univerzitet u Tuzli, Rudarsko-geološko-građevinski fakultet Tuzla, Univerzitetska broj 2, Tuzla, Bosna i Hercegovina, e - mail: mirsad.topalovic@untz.ba

${ }^{4}$ Nedim Osmić, dipl. inž. građ., Vodo-ins d.o.o. Tuzla, II Tuzlanske brigade broj 66, Tuzla, Bosna i Hercegovina, e-mail: nedim.osmic@ hotmail.com
} 
Contemporary achievements in civil engineering 22. April 2016. Subotica, SERBIA

\section{SAVIJANJE ŠTAPA PO METODI KONAČNIH RAZLIKA}

\subsection{Jednačine savijanja štapa po teoriji drugog reda}

Teorija drugog reda se bazira na pretpostavkama o malim deformacijskim veličinama $\varepsilon<<1, \varphi<<1$ i linearnoj vezi između napona i dilatacija (materijalna linearnost) [1]. Veličine pomjeranja napadnih tačaka spoljašnjih sila u ovoj teoriji se uzimaju $u$ proračun, a uslovi ravnoteže uspostavljaju na deformisanom nosaču.

Pri proračunu se smatra da opterećenje štapa prije i poslije deformacije ostaje istog intenziteta i pravca.

Iz jednačina koje opisuju statičko-deformacijsko stanje štapa dobija se nehomogena diferencijalna jednačina po teoriji drugog reda u obliku [2]:

$$
\frac{\mathrm{d}^{2}}{\mathrm{dx^{2 }}}\left[\mathrm{EI}(\mathrm{x}) \frac{\mathrm{d}^{2} \mathrm{v}}{\mathrm{dx}^{2}}\right]-\frac{\mathrm{d}}{\mathrm{dx}}\left(\mathrm{H}(\mathrm{x}) \frac{\mathrm{dv}}{\mathrm{dx}}\right)=\mathrm{p}_{\mathrm{y}}-\frac{\mathrm{d}^{2}}{\mathrm{dx}^{2}}\left[\mathrm{EI}(\mathrm{x}) \cdot \alpha_{\mathrm{t}} \frac{\Delta \mathrm{t}}{\mathrm{h}}\right]
$$

U jednačini (1) kao nepoznate veličine su pomjeranja v i komponente presječnih sila $\mathrm{H}(\mathrm{x})$. Za neke slučajeve u praksi se postiže dovoljna tačnost rješenja ako se usvoji da je normalna sila u štapu $\mathrm{H}=\mathrm{S}$, gdje je $\mathrm{S}$-normalna sila u štapu određena po teoriji prvog reda.

Za slučaj prizmatičnih štapova opterećenih transverzalnim opterećenjem $p_{y}$ sa konstantnom krutosti na savijanje EI=const. i aksijalnom silom $\mathrm{H}=$ const. diferencijalna jednačina (1) dobija sljedeći oblik:

$$
\frac{\mathrm{d}^{4} \mathrm{v}}{\mathrm{dx^{4 }}} \pm \mathrm{k}^{2} \frac{\mathrm{d}^{2} \mathrm{v}}{\mathrm{dx^{2 }}}=\frac{\mathrm{p}_{\mathrm{y}}}{\mathrm{EI}} ; \quad \mathrm{k}^{2}=\frac{\mathrm{S}}{\mathrm{EI}}
$$

Dvostrukom integracijom izraza (2) slijedi:

$$
\frac{\mathrm{d}^{2} \mathrm{v}}{\mathrm{dx}^{2}}=\frac{\mathrm{M} \pm \mathrm{S} \cdot \mathrm{v}}{\mathrm{EI}}
$$

Jednačine (2) i (3) su diferencijalne jednačine elastične linije pravog štapa po linearizovanoj teoriji drugog reda. U tim jednačinama su nepoznata pomjeranja $\mathrm{v}$ ose štapa, a normalne sile $\mathrm{S}$ su poznate i određene po teoriji prvog reda.

\subsection{Savijanje štapa primjenom metode konačnih razlika}

Metoda konačnih razlika (MKR) predstavlja numerički postupak rješavanja diferencijalne jednačine u tački. Ako štap podijelimo na više tačaka, odnosno dijelova onda rješenje diferencijalne jednačine dobijamo za pojedine tačke podjele.

$\mathrm{Na}$ štapu i-k uočimo tačku m u kojoj tražimo rješenje diferencijalne jednačine (3) i u okolini te tačke napravimo podjelu na dijelove dužine $\Delta \mathrm{x}$, slika 1 . 

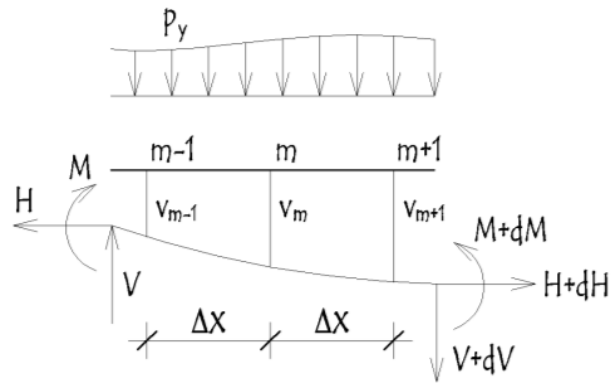

Slika 1. Prikaz opterećenja i funkcije ugiba u okolini tačke štapa

Funkcija ugiba u okolini tačke „m“ se može razviti u Taylor-ov red unaprijed oblika [3]:

$$
\mathrm{v}_{\mathrm{m}+1}=\mathrm{v}_{\mathrm{m}}+\Delta \mathrm{x}\left(\frac{\mathrm{dv}}{\mathrm{dx}}\right)_{\mathrm{m}}+\frac{\Delta \mathrm{x}^{2}}{2 !}\left(\frac{\mathrm{d}^{2} \mathrm{v}}{\mathrm{dx}^{2}}\right)_{\mathrm{m}}+\frac{\Delta \mathrm{x}^{3}}{3 !}\left(\frac{\mathrm{d}^{3} \mathrm{v}}{\mathrm{dx^{3 }}}\right)_{\mathrm{m}}+\frac{\Delta \mathrm{x}^{4}}{4 !}\left(\frac{\mathrm{d}^{4} \mathrm{v}}{\mathrm{dx^{4 }}}\right)_{\mathrm{m}}+\ldots
$$

Razvoj reda unazad je oblika:

$$
\mathrm{v}_{\mathrm{m}-1}=\mathrm{v}_{\mathrm{m}}-\Delta \mathrm{x}\left(\frac{\mathrm{dv}}{\mathrm{dx}}\right)_{\mathrm{m}}+\frac{\Delta \mathrm{x}^{2}}{2 !}\left(\frac{\mathrm{d}^{2} \mathrm{v}}{\mathrm{dx^{2 }}}\right)_{\mathrm{m}}-\frac{\Delta \mathrm{x}^{3}}{3 !}\left(\frac{\mathrm{d}^{3} \mathrm{v}}{\mathrm{dx^{3 }}}\right)_{\mathrm{m}}+\frac{\Delta \mathrm{x}^{4}}{4 !}\left(\frac{\mathrm{d}^{4} \mathrm{v}}{\mathrm{dx}^{4}}\right)_{\mathrm{m}}+\ldots
$$

Ako uzmemo u obzir prva dva člana reda, a ostatak zanemarimo razlika između izraza (4) i (5) predstavlja nagib tangente na elastičnu liniju oblika:

$$
\left(\frac{\mathrm{dv}}{\mathrm{dx}}\right)_{\mathrm{m}}=\frac{\mathrm{v}_{\mathrm{m}+1}-\mathrm{v}_{\mathrm{m}-1}}{2 \Delta \mathrm{x}}
$$

Zbir prva tri člana reda daje krivinu štapa u tački m oblika:

$$
\left(\frac{\mathrm{d}^{2} \mathrm{v}}{\mathrm{dx^{2 }}}\right)_{\mathrm{m}}=\frac{\mathrm{v}_{\mathrm{m}-1}-2 \mathrm{v}_{\mathrm{m}}+\mathrm{v}_{\mathrm{m}+1}}{\Delta \mathrm{x}^{2}}
$$

Kada izraz za krivinu štapa u tački m (7) zamijenimo u jednačinu (3) slijedi jednačina elastične linije štapa po linearizovanoj teoriji drugog reda i metodi konačnih razlika oblika:

$$
\frac{\mathrm{v}_{\mathrm{m}-1}-2 \mathrm{v}_{\mathrm{m}}+\mathrm{v}_{\mathrm{m}+1}}{\Delta \mathrm{x}^{2}}=\frac{\mathrm{M}_{\mathrm{m}} \pm S_{\mathrm{m}} \cdot \mathrm{v}_{\mathrm{m}}}{\mathrm{EI}_{\mathrm{m}}}
$$

Jednačina (8) se rješava iterativno. Za poznatu krutost na savijanje poprečnog presjeka $\mathrm{EI}_{\mathrm{m}} \mathrm{i}$ aksijalnu silu $\mathrm{S}_{\mathrm{m}}$ dobijenu po teoriji prvog reda u tački $\mathrm{m}$ u i-tom iterativnom koraku izraz (8) je oblika [4]:

$$
v_{m-1}^{i}-2 v_{m}^{i}+v_{m+1}^{i}=\frac{\Delta x^{2}}{E I_{m}}\left(M_{m} \pm S_{m} \cdot v_{m}^{i-1}\right)
$$




\section{$4^{\text {th }}$}

Contemporary achievements in civil engineering 22. April 2016. Subotica, SERBIA

\section{PRORAČUN SISTEMA ŠTAPOVA}

Kod proračuna sistema štapova koji čine nosač potrebno je svaki štap podijeliti na manje elemente. Elementi su međusobno povezani čvorovima u kojim se za svaki čvor postavlja jednačina (9). Na slici 2 je prikazana podjela štapa i-k na dijelove.

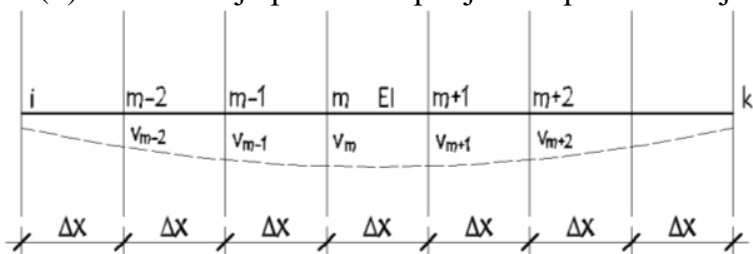

Slika 2. Podjela štapa na elemente

Za podjelu štapa prema slici 2 jednačine savijanja štapa u tačkama $m-1, \mathrm{~m}$ i $\mathrm{m}+1$ po metodi konačnih razlika su oblika:

$$
\begin{aligned}
& v_{m-2}^{i}-2 v_{m-1}^{i}+v_{m}^{i}=\frac{\Delta x^{2}}{E I_{m-1}}\left(M_{m-1} \pm S_{m-1} \cdot v_{m-1}^{i-1}\right) \\
& v_{m-1}^{i}-2 v_{m}^{i}+v_{m+1}^{i}=\frac{\Delta x^{2}}{E I_{m}}\left(M_{m} \pm S_{m} \cdot v_{m}^{i-1}\right) \\
& v_{m}^{i}-2 v_{m+1}^{i}+v_{m+2}^{i}=\frac{\Delta x^{2}}{E I_{m+1}}\left(M_{m+1} \pm S_{m+1} \cdot v_{m+1}^{i-1}\right)
\end{aligned}
$$

Sistem jednačina (10) može se napisati u matričnom obliku:

$$
[\mathrm{A}] \cdot[\mathrm{v}]=[\mathrm{B}]
$$

gdje je: [A] -matrica koeficijenata uz pomjeranja, [v] -matrica kolona nepoznatih pomjeranja i $[\mathrm{B}]$-matrica slobodnih članova. Pri podjeli štapa za neprekidnost funkcije ugiba potrebno je definisati vanjske čvorove. Vanjski čvorovi su izvan predmetnog štapa. Definisanjem vanjskih čvorova javljaju se dodatna nepoznata pomjeranja. Ova pomjeranja određujemo iz rubnih uslova. Rubni uslovi zavise od veze između štapova i veze sa okolinom. Prema tome razlikujemo dvije vrste veza: (a) zglobna veza, (b) uklještenje. Na slici 3 su prikazane navedene vrste veza [5].

a)
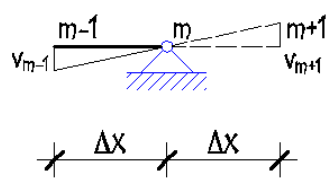

Slika 3. Rubni uslovi štapa b)
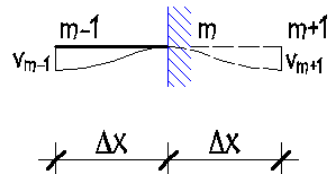

Za zglobnu vezu štapa sa osloncem rubni uslov je:

$$
\left(\frac{\mathrm{d}^{2} \mathrm{v}}{\mathrm{dx^{2 }}}\right)_{\mathrm{m}}=\frac{\mathrm{v}_{\mathrm{m}-1}-2 \mathrm{v}_{\mathrm{m}}+\mathrm{v}_{\mathrm{m}+1}}{\Delta \mathrm{x}^{2}}=0 \Rightarrow \quad \mathrm{v}_{\mathrm{m}+1}=-\mathrm{v}_{\mathrm{m}-1}
$$


Савремена достигнућа у грађевинарству 22. април 2016. Суботица, СРБИЈА

Za uklještenje uslovi su sljedeći:

$$
\left(\frac{\mathrm{dv}}{\mathrm{dx}}\right)_{\mathrm{m}}=\frac{\mathrm{v}_{\mathrm{m}+1}-\mathrm{v}_{\mathrm{m}-1}}{2 \Delta \mathrm{x}}=0 \quad \Rightarrow \quad \mathrm{v}_{\mathrm{m}+1}=\mathrm{v}_{\mathrm{m}-1}
$$

\section{NUMERIČKI PRIMJERI}

U prvom primjeru je analiziran stub na kojem su određeni uticaji drugog reda po metodi konačnih razlika. Krutost na savijanje poprečnog presjeka je: EI=11922,19 kNm².

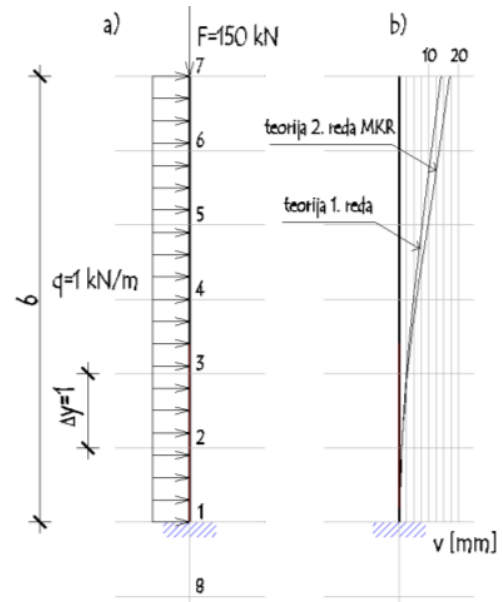

Matrica koeficijenata uz pomjeranja je oblika:

$$
[\mathrm{A}]=\left[\begin{array}{cccccc}
2 & 0 & 0 & 0 & 0 & 0 \\
-2 & 1 & 0 & 0 & 0 & 0 \\
1 & -2 & 1 & 0 & 0 & 0 \\
0 & 1 & -2 & 1 & 0 & 0 \\
0 & 0 & 1 & -2 & 1 & 0 \\
0 & 0 & 0 & 1 & -2 & 1
\end{array}\right]
$$

Slika 4. Primjer 1

Nepoznata pomjeranja su: $[\mathrm{v}]^{\mathrm{T}}=\left[\begin{array}{llllll}\mathrm{v}_{2} & \mathrm{v}_{3} & \mathrm{v}_{4} & \mathrm{v}_{5} & \mathrm{v}_{6} & \mathrm{v}_{7}\end{array}\right]^{\mathrm{T}}$

Matrica slobodnih članova u pojedinim iteracijama je oblika:

$$
[\mathrm{B}]^{(1)}=\left[\begin{array}{c}
0,00151 \\
0,00105 \\
0,000671 \\
0,000377 \\
0,000168 \\
0,0000419
\end{array}\right] \text {; }
$$$$
[\mathrm{B}]^{(2)}=\left[\begin{array}{c}
0,001681 \\
0,001211 \\
0,000812 \\
0,000488 \\
0,000243 \\
0,0000798
\end{array}\right] \text {; }
$$

$$
[\mathrm{B}]^{(3)}=\left[\begin{array}{c}
0,001716 \\
0,001244 \\
0,000841 \\
0,000511 \\
0,000259 \\
0,0000882
\end{array}\right] \text {; }
$$

\begin{tabular}{|c|c|c|c|c|c|c|c|c|c|c|c|c|c|c|c|}
\hline \multirow{2}{*}{ Čvor } & \multicolumn{3}{|c|}{ 1. iteracija } & \multicolumn{3}{|c|}{ 2. iteracija } & \multicolumn{3}{|c|}{ 3. iteracija } & \multicolumn{3}{|c|}{ 4. iteracija } & \multirow{2}{*}{$\begin{array}{l}\text { Proračun } \\
\mathrm{M}[\mathrm{kNm}]\end{array}$} & \multicolumn{2}{|c|}{ Tower } \\
\hline & $\mathrm{M}[\mathrm{kNm}]$ & $\mathrm{v}[\mathrm{mm}]$ & $\mathrm{S} \cdot \mathrm{v}[\mathrm{kNm}]$ & $\mathrm{M}[\mathrm{kNm}]$ & $\mathrm{v}[\mathrm{mm}]$ & $\mathrm{S} \cdot \mathrm{v}[\mathrm{kNm}]$ & $\mathrm{M}[\mathrm{kNm}]$ & $\mathrm{v}[\mathrm{mm}]$ & $\mathrm{S} \cdot \mathrm{v}[\mathrm{kNm}]$ & $\mathrm{M}[\mathrm{kNm}]$ & $\mathrm{v}[\mathrm{mm}]$ & $\mathrm{S} \cdot \mathrm{v}[\mathrm{kNm}]$ & & $\mathrm{M}[\mathrm{kNm}]$ & $\mathrm{v}[\mathrm{mm}]$ \\
\hline 1 & 18,00 & 0,00 & 2,04 & 20,04 & 0,00 & 2,46 & 20,46 & 0,00 & 2,53 & 20,53 & 0,00 & 2,54 & 20,54 & 20,48 & 0,00 \\
\hline 2 & 12,50 & 0,68 & 1,94 & 14,44 & 0,84 & 2,33 & 14,83 & 0,86 & 2,40 & 14,90 & 0,86 & 2,42 & 14,92 & 14,68 & 0,78 \\
\hline 3 & 8,00 & 2,42 & 1,68 & 9,68 & 2,89 & 2,02 & 10,02 & 2,96 & 2,09 & 10,09 & 2,97 & 2,10 & 10,10 & 10,06 & 2,82 \\
\hline 4 & 4,50 & 4,83 & 1,32 & 5,82 & 5,76 & 1,59 & 6,09 & 5,90 & 1,65 & 6,15 & 5,93 & 1,65 & 6,15 & 6,13 & 5,70 \\
\hline 5 & 2,00 & 7,62 & 0,90 & 2,90 & 9,11 & 1,09 & 3,09 & 9,36 & 1,13 & 3,13 & 9,40 & 1,13 & 3,13 & 3,11 & 9,10 \\
\hline 6 & 0,50 & 10,59 & 0,45 & 0,95 & 12,70 & 0,55 & 1,05 & 13,07 & 0,57 & 1,07 & 13,14 & 0,57 & 1,07 & 1,06 & 12,77 \\
\hline 7 & 0,00 & 13,60 & 0,00 & 0,00 & 16,38 & 0,00 & 0,00 & 16,87 & 0,00 & 0,00 & 16,96 & 0,00 & 0,00 & 0,00 & 16,54 \\
\hline
\end{tabular}

$$
[\mathrm{B}]^{(4)}=\left[\begin{array}{c}
0,001722 \\
0,001250 \\
0,000846 \\
0,000515 \\
0,000262 \\
0,0000897
\end{array}\right]
$$

Tabela 1. Prikaz rezultata proračuna iz 1. primjera 


\section{$4^{\text {th }}$}

Contemporary achievements in civil engineering 22. April 2016. Subotica, SERBIA

U drugom primjeru je analiziran nosač na dva polja. Rezultati proračuna su prikazani za podjelu štapova na dijelove od $1 \mathrm{~m}$ (tabela 2 ) i na $0,5 \mathrm{~m}$ (tabela 3 ). Rezultati proračuna su uspoređeni sa linearnim proračunom i rezultatima iz programskog paketa [6]. Krutost na savijanje poprečnog presjeka štapova je: $\mathrm{EI}=1987,90 \mathrm{kNm}^{2}$.

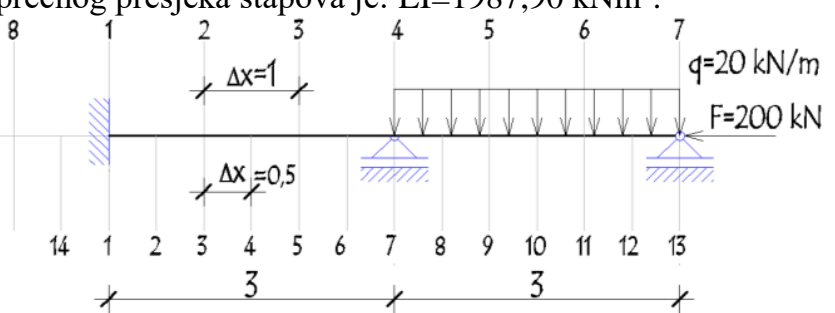

Slika 5. Primjer 2

Tabela 2. Prikaz rezultata proračuna iz 2. primjera, $\Delta x=1 \mathrm{~m}$

\begin{tabular}{|c|c|c|c|c|c|c|c|c|c|c|c|c|c|c|c|c|c|}
\hline \multirow{2}{*}{ Čvor } & \multicolumn{3}{|c|}{ 1. iteracija } & \multicolumn{5}{|c|}{ 2. iteracija } & \multicolumn{4}{|c|}{ 3. iteracija } & \multirow{2}{*}{$\begin{array}{l}\text { Proračun } \\
\mathrm{M}[\mathrm{kNm}]\end{array}$} & \multicolumn{2}{|c|}{ Tower } & \multicolumn{2}{|c|}{ Razlika [\%] } \\
\hline & $\mathrm{M}[\mathrm{kNm}]$ & $\mathrm{v}[\mathrm{mm}]$ & $\mathrm{S} \cdot \mathrm{v}[\mathrm{kNm}]$ & $\mathrm{M}+\mathrm{S} \cdot \mathrm{v}$ & $\mathrm{v}[\mathrm{mm}]$ & $\mathrm{k}[1 / \mathrm{m}]$ & $\mathrm{M}[\mathrm{kNm}]$ & $\mathrm{S} \cdot \mathrm{v}[\mathrm{kNm}]$ & $\mathrm{M}+\mathrm{S} \cdot \mathrm{v}$ & $\mathrm{v}[\mathrm{mm}]$ & $\mathrm{k}[1 / \mathrm{m}]$ & $\mathrm{M}[\mathrm{kNm}]$ & & $\mathrm{M}[\mathrm{kNm}]$ & $\mathrm{v}[\mathrm{mm}]$ & M & v \\
\hline 1 & 16 & & م00 & 4 & 0.00 & $-0,00250$ & 407 & م & 407 & 0,00 & $-0,00254$ & 505 & 505 & 679 & & &, 00 \\
\hline 2 & & & -0 & ),33 & $-1,25$ & 0, & $-0,32$ & $-0,03$ & $-0,35$ & $-1,27$ & 0,00018 & $-0,36$ & $-0,36$ & $-0,15$ & $-1,23$ & $-138,55$ & $-3,25$ \\
\hline 3 & 38 & $-2,16$ & $-0,43$ & $-6,81$ & $-2,34$ & 0,00343 & $-6,82$ & $-0,04$ & $-6,85$ & $-2,36$ & 0,00345 & $-6,86$ & $-6,86$ & $-7,06$ & $-2,38$ & 2,86 & 0,84 \\
\hline 4 & & & & $-12,65$ & 0,0 & & $-9,68$ & 0 , & -9 & 0,00 & 92 & -9 & , & -13 & & 6,30 & 00 \\
\hline 5 & & & & & & & 12,88 & & & 7,2 & $-0,00655$ & 13,02 & & 12,43 & & $-4,75$ & $-13,57$ \\
\hline 6 & 15,78 & 7,23 & 1,45 & 17,23 & 7,94 & $-0,00867$ & 17,24 & 0,14 & 17,38 & 8,01 & $-0,00874$ & 17,37 & 17,37 & 17,01 & 7,17 & $-2,14$ & $-11,72$ \\
\hline
\end{tabular}

Tabela 3. Prikaz rezultata proračuna iz 2. primjera, $\Delta x=0,5 \mathrm{~m}$

\begin{tabular}{|c|c|c|c|c|c|c|c|c|c|c|c|c|c|c|c|c|c|}
\hline \multirow{2}{*}{ Čvor } & \multicolumn{3}{|c|}{ 1. iteracija } & \multicolumn{5}{|c|}{ 2. iteracija } & \multicolumn{4}{|c|}{ 3. iteracija } & \multirow{2}{*}{$\begin{array}{l}\text { Proračun } \\
\mathrm{M}[\mathrm{kNm}]\end{array}$} & \multicolumn{2}{|c|}{ Tower } & \multicolumn{2}{|c|}{ Razlika [\%] } \\
\hline & $\mathrm{M}[\mathrm{kNm}]$ & $\mathrm{v}[\mathrm{mm}]$ & $\mathrm{S} \cdot \mathrm{v}[\mathrm{kNm}]$ & $\mathrm{M}+\mathrm{S} \cdot \mathrm{v}$ & $\mathrm{v}[\mathrm{mm}]$ & $\mathrm{k}[1 / \mathrm{m}]$ & $\mathrm{M}[\mathrm{kNm}]$ & $S \cdot v[\mathrm{kNm}]$ & $\mathrm{M}+\mathrm{S} \cdot \mathrm{v}$ & $\mathrm{v}[\mathrm{mm}]$ & $\mathrm{k}[1 / \mathrm{m}]$ & $\mathrm{M}[\mathrm{kNm}]$ & & $\mathrm{M}[\mathrm{kNm}]$ & $\mathrm{v}[\mathrm{mm}]$ & M & $\mathrm{v}$ \\
\hline 1 & 6,16 & 0,00 & 0,00 & 6,16 & 0,00 & $-0,00336$ & 6,68 & 0,00 & 6,68 & 0,00 & $-0,00336$ & 6,68 & 6,68 & 6,79 & 0,00 & 1,63 & 0 \\
\hline 2 & 3,02 & $-0,36$ & 0,07 & 3,09 & $-0,42$ & $-0,00160$ & 3,18 & 0,01 & 3,19 & $-0,42$ & $-0,00164$ & 3,26 & 3,26 & 3,36 & $-0,40$ & 2,97 & $-5,00$ \\
\hline 3 & $-0,11$ & $-1,11$ & $-0,22$ & $-0,33$ & $-1,24$ & 0,00020 & $-0,40$ & $-0,03$ & $-0,42$ & $-1,25$ & 0,00024 & $-0,48$ & $-0,48$ & $-0,15$ & $-1,23$ & $-218,06$ & $-1,63$ \\
\hline 4 & $-3,25$ & $-1,84$ & $-0,37$ & $-3,62$ & $-2,01$ & 0,00184 & $-3,66$ & $-0,03$ & $-3,69$ & $-2,02$ & 0,00184 & $-3,66$ & $-3,66$ & $-3,65$ & $-2,03$ & $-0,21$ & 0,49 \\
\hline 5 & $-6,38$ & $-2,16$ & $-0,43$ & $-6,81$ & $-2,32$ & 0,00340 & $-6,76$ & $-0,03$ & $-6,79$ & $-2,33$ & 0,00340 & $-6,76$ & $-6,76$ & $-7,06$ & $-2,38$ & 4,27 & 2,10 \\
\hline 6 & $-9,52$ & $-1,68$ & $-0,34$ & $-9,86$ & $-1,78$ & 0,00496 & $-9,86$ & $-0,02$ & $-9,88$ & $-1,79$ & 0,00500 & $-9,94$ & $-9,94$ & $-10,30$ & $-1,84$ & 3,50 & 2,72 \\
\hline 7 & $-12,65$ & 0,00 & 0,00 & $-12,65$ & 0,00 & 0,00648 & $-12,88$ & 0,00 & $-12,88$ & 0,00 & 0,00656 & $-13,04$ & $-13,04$ & $-13,28$ & 0,00 & 1,80 & 0,00 \\
\hline 8 & 1,96 & 3,07 & 0,61 & 2,57 & 3,40 & $-0,00132$ & 2,62 & 0,07 & 2,69 & 3,43 & $-0,00136$ & 2,70 & 2,70 & 2,11 & 3,34 & $-28,13$ & $-2,69$ \\
\hline 9 & 11,57 & 5,90 & 1,18 & 12,75 & 6,47 & $-0,00640$ & 12,72 & 0,11 & 12,84 & 6,52 & $-0,00644$ & 12,80 & 12,80 & 12,43 & 6,41 & $-2,99$ & $-1,72$ \\
\hline 10 & 16,17 & 7,27 & 1,45 & 17,62 & 7,94 & $-0,00884$ & 17,57 & 0,13 & 17,71 & 8,00 & $-0,00888$ & 17,65 & 17,65 & 17,44 & 7,89 & $-1,22$ & $-1,39$ \\
\hline 11 & 15,78 & 6,60 & 1,32 & 17,10 & 7,20 & $-0,00864$ & 17,18 & 0,12 & 17,30 & 7,26 & $-0,00876$ & 17,41 & 17,41 & 17,01 & 7,17 & $-2,38$ & $-1,26$ \\
\hline 12 & 10,39 & 3,96 & 0,79 & 11,18 & 4,30 & $-0,00560$ & 11,13 & 0,07 & 11,20 & 4,33 & $-0,00560$ & 11,13 & 11,13 & 11,15 & 4,29 & 0,16 & $-0,93$ \\
\hline 13 & 0,00 & 0,00 & 0,00 & 0,00 & 0,00 & 0,00000 & 0,00 & 0,00 & 0,00 & 0,00 & 0,00000 & 0,00 & 0,00 & 0,00 & 0,00 & 0,00 & 0,00 \\
\hline
\end{tabular}

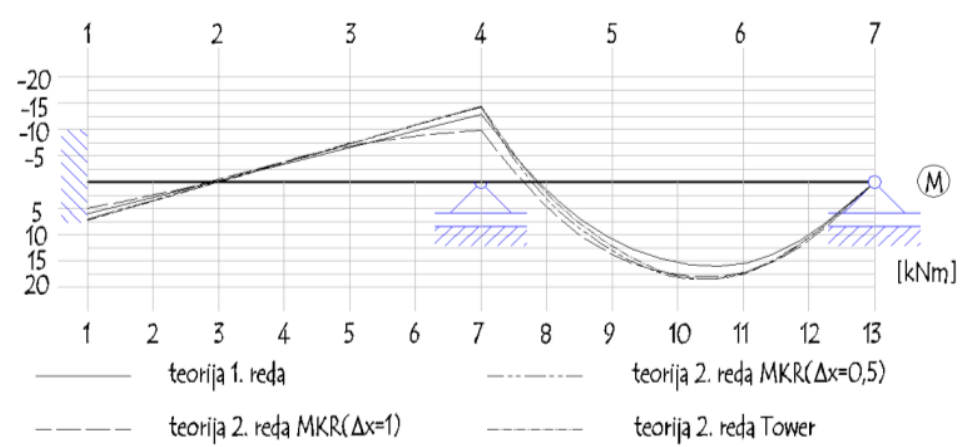

Slika 6. Dijagrami momenata savijanja nosača iz 2. primjera 


\section{ZAKLJUČAK}

Uspostavljanjem uslova ravnoteže na deformisanom nosaču dobijaju se realniji rezultati proračuna sila i deformacija. Geometrijski nelinearan problem primjenom metode konačnih razlika je riješen pomoću sistema linearnih jednačina. Iz prikazanih primjera zaključujemo da rezultati proračuna zavise od gustine podjele štapova na manje elemente. Sa većim elementima podjele momenti savijanja i deformacije u unutrašnjim čvorovima su približni analitičkom rješenju, dok su za vanjske čvorove odstupanja značajna. Sa povećanjem gustine mreže do dužina pojedinih elemenata od $0,5 \mathrm{~m}$ rješenje nosača je približno rezultatima dobijenim u programskom paketu.

Odstupanja u proračunu po metodi konačnih razlika u odnosu na programski paket se kreću oko 3\% što je u prihvatljivim granicama. U tačkama nosača sa nultim momentima razlike su značajne zbog toga što mreža elemenata ne pokriva uske zone gdje krivina deformacione linije mijenja znak.

Rezultati proračuna po teoriji drugog reda u odnosu na teoriju prvog reda razlikuju se do $\approx 10 \%$ u prikazanim primjerima.

\section{LITERATURA}

[1] Đurić, M.: Stabilnost i dinamika konstrukcija, Građevinski fakultet, Beograd, 1980., str. 1-4;

[6] Čaušević, M.: Statika konstrukcija po teoriji drugog reda, Glas, Banja Luka, 1983., str. 15-20;

[7] http://www.mathematik.uni-dortmund.de/ kuzmin/cfdintro/lecture4.pdf, preuzeto 18.01.2016.

[8] Maglajlić, Z.: Metoda relaksacije, Građevinski fakultet u Sarajevu, Sarajevo, 2008., str. 10-24;

[9] Hajdin, N.: Teorija površinskih nosača, Naučna knjiga, Beograd, 1989., str. 66;

[10] Tower 6, Uputstvo za rad sa programom, Radimpex, Beograd.

\section{DETERMINATION OF THE IMPACT ACCORDING TO THE SECOND ORDER THEORY USING FINITE DIFFERENCE METHOD}

Summary: This paper presents the procedure of numerical modeling geometric nonlinearity beam using the finite difference method. The calculation cross section forces and displacements is carried iterative procedures taking into account the effects of the second order. Described method balance system is established on a deformed beam. This way of cutting forces have their own contribution to the bending moments and deformation. Presents a calculation method can be modeled geometric nonlinearity beam with constant or variable cross section. The calculations are done numerically, and the results are controlled by the software package Tower. The present numerical 


\section{$4^{\text {th }}$ inTERnATIONAL CONFERENCE}

Contemporary achievements in civil engineering 22. April 2016. Subotica, SERBIA

results of displacements and forces, and compared with the results obtained in the application pack. Through numerical examples presented the calculation process and analysis of results.

Keywords: geometric nonlinearity, the theory of second order. 